\title{
Fibrinogen concentrate administration attributes to significant reductions of blood loss and transfusion requirements in thoracic aortic repair
}

Koji Yamamoto ${ }^{1 *}$, Akihiko Usui ${ }^{2}$ and Junki Takamatsu ${ }^{3}$

\begin{abstract}
Background: Repair of thoracic aortic aneurysm (TAA) is often associated with massive hemorrhage aggravated by dilutional coagulopathy with severe hypofibrinogenemia. Although only fresh frozen plasma (FFP) is available for acquired hypofibrinogenemia in Japan, the hemostatic effect of FFP has not been enough for dilutional coagulopathy in TAA surgery. There are increasing reports suggesting that fibrinogen concentrate may be effective in controlling perioperative bleeding and reducing transfusion requirements.

Methods: We retrospectively analyzed the hemostatic effect of fibrinogen concentrate compared with FFP in total 49 cases of elective TAA surgery. In 25 patients, fibrinogen concentrate was administered when the fibrinogen level was below $150 \mathrm{mg} / \mathrm{dL}$ at the cardiopulmonary bypass (CPB) termination. The recovery of fibrinogen level, blood loss, and transfused units during surgery were compared between cases of this agent and FFP $(n=24)$.

Results: We observed rapid increases in plasma fibrinogen level and subsequent improvement in hemostasis by administration of fibrinogen concentrate after CPB termination. The average volume of total blood loss decreased by $64 \%$ and the average number of transfused units was reduced by $58 \%$ in cases of fibrinogen concentrate given, in comparison with cases of only FFP transfused for fibrinogen supplementation.
\end{abstract}

Conclusions: In patients showing severe hypofibrinogenemia during TAA surgery, timely administration of fibrinogen concentrate just after removal from CPB is effective for hemostasis, and therefore in reducing blood loss and transfused volumes.

Keywords: Massive hemorrhage, Thoracic aortic aneurysm, Cardiopulmonary bypass, Dilutional coagulopathy, Hypofibrinogenemia

\section{Background}

Aortic repair surgery for patients with thoracic aortic aneurysm (TAA) using cardiopulmonary bypass (CPB) is frequently complicated by massive hemorrhage, most commonly aggravated by dilutional coagulopathy with severe hypofibrinogenaemia. Patients with aortic aneurysms often show silent disseminated intravascular coagulation preoperatively [1]. Impairment of coagulation may be caused by $\mathrm{CPB}$ and be further aggravated by hypothermic circulatory arrest [2]. For example, the baseline plasma fibrinogen levels have been reported to decrease by $34 \%$ to $58 \%$

\footnotetext{
*Correspondence: kojiy@med.nagoya-u.ac.jp

'Department of Transfusion Medicine, Nagoya University Hospital, 65

Tsurumai, Showa, Nagoya 466-8560, Japan

Full list of author information is available at the end of the article
}

during $\mathrm{CPB}[3,4]$. In general, failure to manage the coagulopathy and to control microvascular bleeding in cardiac surgery could lead to the increased risk of subsequent morbidity and mortality [5].

Severe hypofibrinogenemia in dilutional coagulopathy during cardiothoracic surgery causes uncontrollable oozing at multiple sites in the surgical field. This bleeding could be stopped only by quick and enough supply of coagulation factors, especially fibrinogen. As the final substrate of coagulation and the ligand of the platelet GPIIb/IIIa receptors, fibrinogen plays a key role in clot formation. Because fibrinogen is the first to fall below a critical value during massive bleeding and hemodilution [6], it would be the critical protein to be supplied first among coagulation factors. Although there are increasing reports describing 
the limitation of fresh frozen plasma (FFP) effect against ongoing severe hypofibrinogenemia in cardiac surgery $[7,8]$, only FFP is currently available for acquired hypofibrinogenemia in Japan. Indeed, cryoprecipitate is not generally supplied from Japanese Red Cross and a purified fibrinogen concentrate derived from pooled human plasma (Fibrinogen HT; Japan Blood Products Organization, Tokyo, Japan) is available only for congenital fibrinogen deficiency in Japan. Fibrinogen concentrate shows a critical effect on fibrinogen recovery and subsequent hemostasis in both hereditary [9] and acquired $[10,11]$ hypofibrinogenemic states, especially in obstetric hemorrhage $[12,13]$, in trauma-induced coagulopathy $[14,15]$, and in cardiovascular surgery $[16,17]$.

The aim of this study is to examine the efficacy of fibrinogen concentrate for reduction in blood loss and transfused volume in TAA surgery. We measured the plasma level of fibrinogen at several time points in patients with TAA surgery and found that severe hypofibrinogenemia progressed during $\mathrm{CPB}$. Because we hypothesized that the quick recovery from severe hypofibrinogenemia would be the most critical for hemostasis in TAA surgery, the hemostatic effect of fibrinogen concentrate was evaluated in comparison with FFP.

\section{Methods}

In this single-center retrospective study, we analyzed the plasma fibrinogen level, total amounts of blood loss, and total transfused units of allogenic blood products in 49 patients undergoing elective surgery of thoracic aortic repair involving CPB. Any type of aortic repair surgery with root/ascending aorta, aortic arch, and descending aorta was eligible in this analysis. We administered fibrinogen concentrate when the fibrinogen level in plasma was below $150 \mathrm{mg} / \mathrm{dL}$ at removal from CPB in 25 patients. The aim of fibrinogen concentrate administration was to maintain fibrinogen levels above $200 \mathrm{mg} / \mathrm{dL}$. The initial fibrinogen dose was 3 to 5 gram (i.e., $50-60 \mathrm{mg}$ of fibrinogen $/ \mathrm{kg}$ ), but additional fibrinogen concentrate was administered repeatedly when the first administration of fibrinogen concentrate could not elevate the fibrinogen level over $200 \mathrm{mg} / \mathrm{dL}$ or achieve complete hemostasis. Meanwhile, age-matched 24 cases in the past 2 years were enrolled as the FFP group, in which only FFP was transfused for correction of hypofibrinogenemia (e.g., < $150 \mathrm{mg} / \mathrm{dL}$ ) or to stop oozing after CPB termination. Red blood cells (RBCs) were administered according to institutional guidelines, e.g., for hemoglobin levels below $8.0 \mathrm{~g} / \mathrm{dL}$ in active hemorrhage. Five-unit FFP was administered when the prothrombin time (PT) INR was larger than 2.0, or the patient was actively bleeding. Ten to fifteen units of PC was administered when the platelet count was below $50 \times 10^{3} / \mu \mathrm{l}$. One unit of RBC contains $130 \mathrm{ml}$ of red blood cells derived from $200 \mathrm{ml}$ of whole blood. Five units of FFP contain $400 \mathrm{ml}$ of whole plasma, while 10 units of platelet concentrate (PC) contain $2-3 \times 10^{11}$ of platelets, both of which were obtained by apheresis. The off-label fibrinogen concentrate substitution therapy was approved by the Institutional Review Board of Nagoya University Hospital and complies with the Declaration of Helsinki. The average volume of total blood loss and the average number of transfusion units were compared between the FFP group and the group of fibrinogen concentrate. The significant difference was evaluated by unpaired $t$-test. Pre- and intra-operative levels of hemoglobin and hemostatic markers (e.g., platelet count, PT, activated partial thromboplastin time (APTT), and plasma fibrinogen level) in each group are shown in Table 1.

\section{Results}

The hemoglobin level and some hemostatic markers before surgery in patients showed no significant differences between the FFP group and the group of fibrinogen concentrates (Table 1). All patients analyzed in this study progressed hypofibrinogenemia during $\mathrm{CPB}$ and their fibrinogen levels frequently fell below $150 \mathrm{mg} / \mathrm{dL}$ at the end of $\mathrm{CPB}$. Platelet counts during $\mathrm{CPB}$ showed lower than $50 \times 10^{3} / \mu \mathrm{l}$ in most cases we analyzed, in which platelet transfusion was required. We show the representative case as Figure 1, in which only FFP was transfused for supplementation of fibrinogen. The fibrinogen level was gradually elevated by three times of transfusion with 5 units of FFP. In spite of large volume of FFP transfusion, we observed little improvement of hemostasis and continuing oozing at the surgical field, resulting in the additional massive transfusion with FFP, RBC, and PC in this case.

On the other hand, we demonstrate representative cases in which fibrinogen concentrate was administered at the end of $\mathrm{CPB}$ as Figures 2, 3 and 4. In the case of

Table 1 Parameters before TAA surgery (baseline) in each group analysed (mean \pm SD)

\begin{tabular}{lcc}
\hline & $\begin{array}{c}\text { Only FFP } \\
(\mathbf{n}=\mathbf{2 4})\end{array}$ & $\begin{array}{c}\text { Fibrinogen concentrate } \\
(\mathbf{n}=\mathbf{2 5})\end{array}$ \\
\hline $\mathrm{Hb}(\mathbf{g} / \mathbf{d L})$ & $13.7 \pm 2.7$ & $14.2 \pm 2.9$ \\
Platelet $(\times \mathbf{1 0 0 0 / \mu L )}$ & $178 \pm 57$ & $153 \pm 38$ \\
PT (sec.) & $11.2 \pm 1.3$ & $11.4 \pm 1.0$ \\
APTT (sec.) & $33.7 \pm 2.6$ & $34.1 \pm 2.8$ \\
Fibrinogen (mg/dL) & & \\
\multicolumn{1}{c}{ Baseline } & $275 \pm 66$ & $268 \pm 57$ \\
$\quad$ End of CPB & $116 \pm 33$ & $108 \pm 39$ \\
$\quad$ End of operation & $141 \pm 36$ & $252 \pm 46^{*}$
\end{tabular}

The fibrinogen levels at the end of CPB and of surgery in each group are also indicated.

TAA: thoracic aortic aneurysm; $C P B$ : cardiopulmonary bypass; $\mathrm{Hb}$ : hemoglobin; $P T$ : prothrombin time; APTT: activated partial thromboplastin time; ${ }^{*} P<0.02$. 


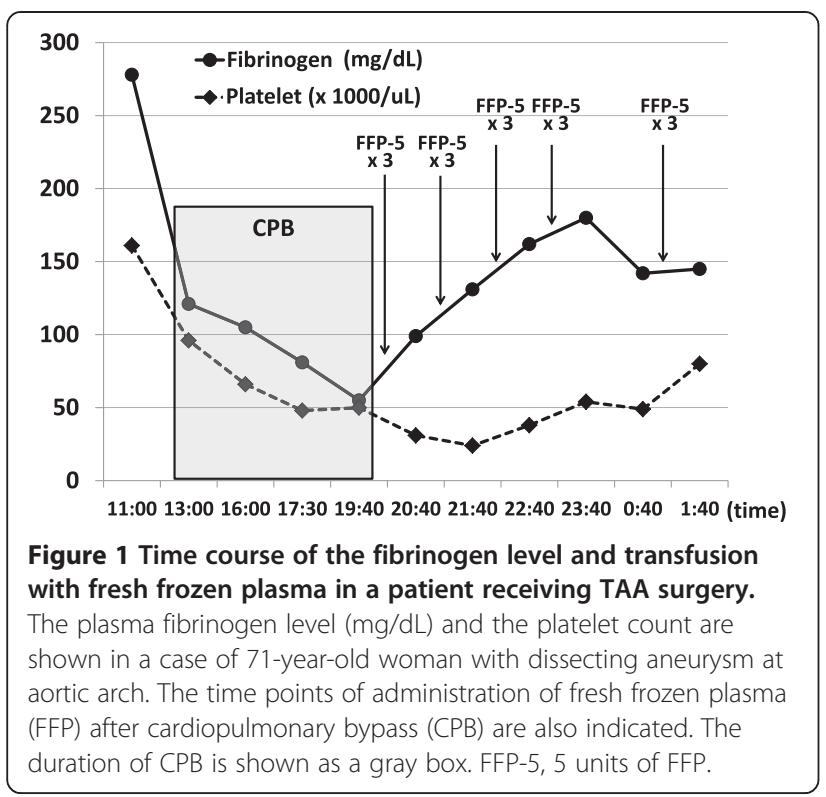

Figure 2, a single administration with 4 gram of fibrinogen concentrate elevated the plasma fibrinogen level by $130 \mathrm{mg} / \mathrm{dL}$, leading to complete hemostasis in a short time. Even though severe hypofibrinogenemia around $100 \mathrm{mg} / \mathrm{dL}$ progressed during CPB in the case of Figure 3, a rapid increase in the plasma fibrinogen level and subsequent hemostasis were achieved by enough supplementation with fibrinogen concentrate. Although the fibrinogen level did not reach over $200 \mathrm{mg} / \mathrm{dL}$ in this case, no more fibrinogen concentrate was necessary because complete hemostasis was achieved after the third administration of fibrinogen concentrate. Also in the case of Figure 4, a dramatic elevation of the fibrinogen level and subsequent complete hemostasis was observed after administration

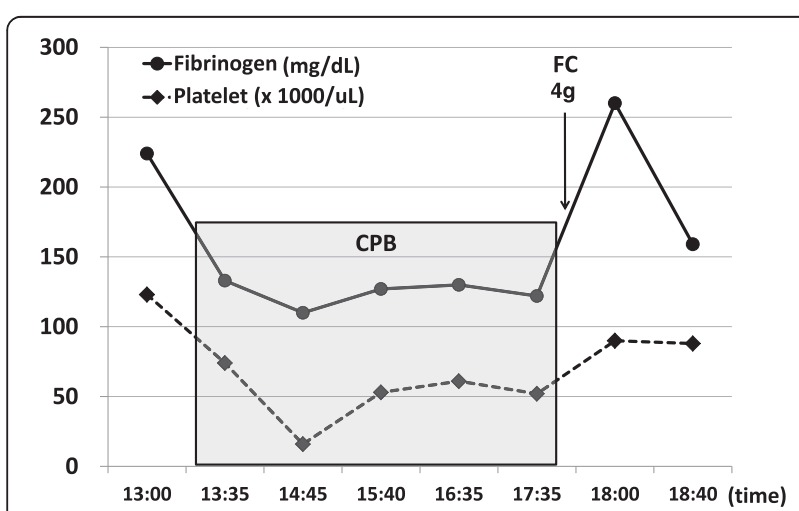

Figure 2 Time course of the fibrinogen level and administration with fibrinogen concentrate in a patient receiving TAA surgery. The plasma fibrinogen level $(\mathrm{mg} / \mathrm{dL})$ and the platelet count are shown in a case of 63-year-old man with replacement of ascending thoracic aorta. The time points of administration of fibrinogen concentrate (FC) after cardiopulmonary bypass (CPB) are also indicated. The duration of $\mathrm{CPB}$ is shown as a gray box.

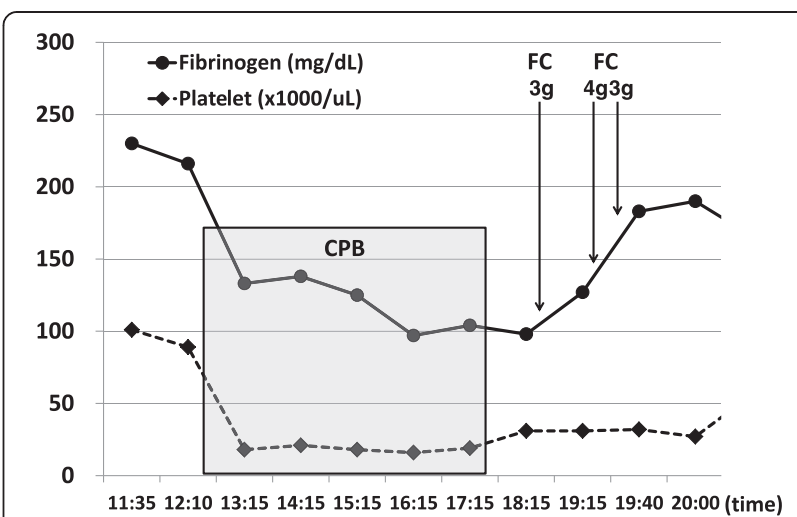

Figure 3 Time course of the fibrinogen level and administration with fibrinogen concentrate in a patient receiving TAA surgery.

The plasma fibrinogen level $(\mathrm{mg} / \mathrm{dL})$ and the platelet count are shown in a case of 45-year-old man with replacement of aortic root. The time points of administration of fibrinogen concentrate (FC) after cardiopulmonary bypass (CPB) are also indicated. The duration of CPB is shown as a gray box.

with 5 gram of fibrinogen concentrate two times although critical hypofibrinogenemia below $100 \mathrm{mg} / \mathrm{dL}$ progressed during $\mathrm{CPB}$. The median dose of fibrinogen administered in the group of fibrinogen concentrate was $8.2 \pm 4.8$ gram. In general, the fibrinogen level at the end of surgery was greater than 200 to $250 \mathrm{mg} / \mathrm{dL}$ in the group of fibrinogen concentrate administered, which was significantly higher in comparison with the FFP group (Table 1). There was no observed safety concern with using fibrinogen concentrate during and after TAA surgery.

We compared total blood loss and transfusion volume in TAA surgery between the FFP group and the group of fibrinogen concentrates (Figure 5). Dramatic decreases in the bleeding volume and transfusion units of allogenic

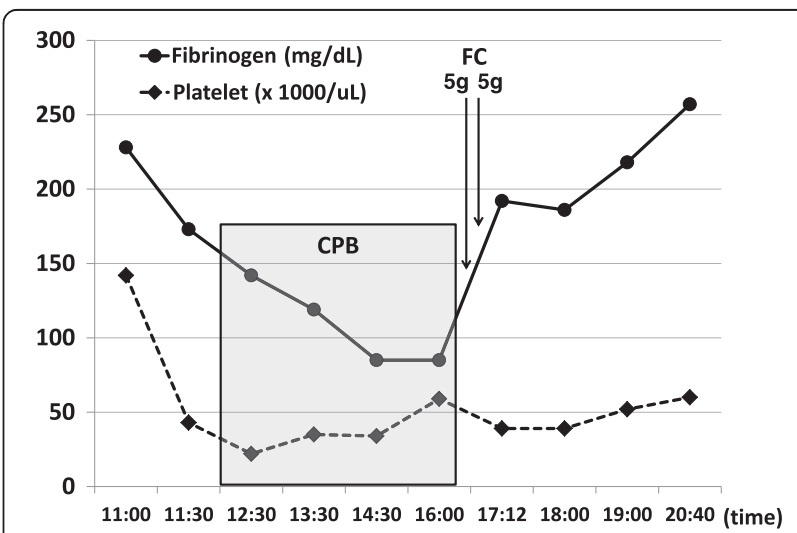

Figure 4 Time course of the fibrinogen level and administration with fibrinogen concentrate in a patient receiving TAA surgery. The plasma fibrinogen level $(\mathrm{mg} / \mathrm{dL})$ and the platelet count are shown in a case of 59-year-old man with dissecting aneurysm of descending thoracic aorta. The time points of administration of fibrinogen concentrate (FC) after cardiopulmonary bypass (CPB) are also indicated. The duration of CPB is shown as a gray box. 


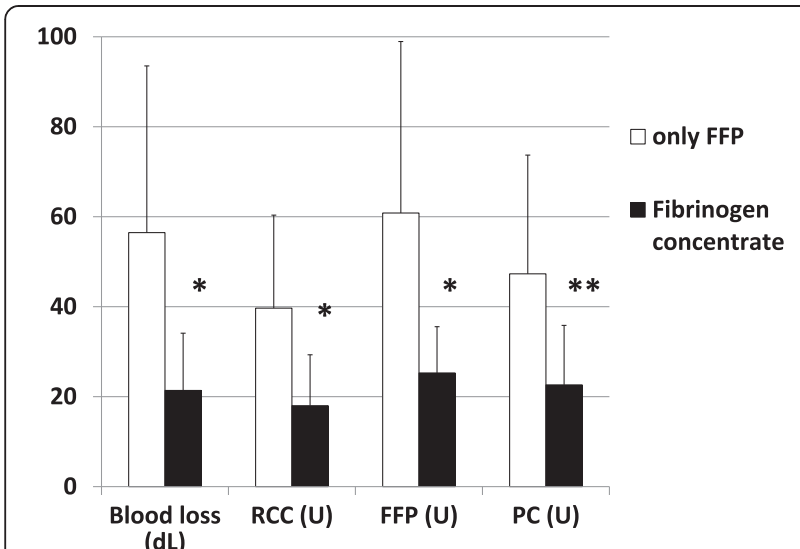

Figure 5 Volume of blood loss and number of transfusion units during TAA surgery. Open bars: cases treated with only FFP $(n=24)$; Closed bars: cases treated with fibrinogen concentrate as well as conventional transfusion $(n=25)$. RBC, red blood cell; FFP, fresh frozen plasma; PC, platelet concentrate. One unit (U) of RBC contains $130 \mathrm{ml}$ of red blood cells derived from $200 \mathrm{ml}$ of whole blood. Five units of FFP contain $400 \mathrm{ml}$ of whole plasma, while 10 units of PC contain $2-3 \times 10^{11}$ of platelets. The data are presented as the mean \pm SD. ${ }^{*} p<0.05 ;{ }^{* *} p<0.01$ (by unpaired $t$-test).

blood components were observed in the group of fibrinogen concentrate. In cases of fibrinogen concentrate given, the average volume of intraoperative blood loss decreased by $64 \%(5,640 \mathrm{ml}$ in the FFP group vs. $2,140 \mathrm{ml}$ in the group of fibrinogen concentrate) and the average number of transfusion units was reduced by $56 \%$ in RBC (39.7 units in the FFP group vs. 18.0 units in the group of fibrinogen concentrate), $61 \%$ in FFP (60.8 units vs. 25.3 units), and $55 \%$ in PC (47.3 units vs. 22.6 units), in comparison with cases in which only FFP was administered. Thus, significant reductions in total blood loss and transfused volume during surgery were achieved by timely administration of fibrinogen concentrate after $\mathrm{CPB}$ in repair of thoracic aortic aneurysms.

\section{Discussion}

We have frequently experienced massive hemorrhage over $5,000 \mathrm{ml}$, which is characterized by microvascular bleeding due to coagulopathy [18], in surgery of thoracic aortic repair. Cardiovascular surgery using $\mathrm{CPB}$ decreases the plasma concentration of coagulation factors primarily by hemodilution with $\mathrm{CPB}$ priming and intravenous fluids [4]. We chased the plasma fibrinogen level in patients with TAA surgery and found that the fibrinogen concentration frequently fell below $150 \mathrm{mg} / \mathrm{dL}$ during CPB (Figures 1, 2, 3 and 4). In several cases, the plasma fibrinogen level reached less than $100 \mathrm{mg} / \mathrm{dL}$ at the end of $\mathrm{CPB}$, as representatively shown in Figure 1 and Figure 4. The $\mathrm{CPB}$-associated reduction of fibrinogen depends, in part, upon the consumptive coagulopathy deteriorated by $\mathrm{CPB}$ through activation of coagulation pathway primarily caused by retransfusion of blood aspirated from the surgical field $[19,20]$. Fibrin clots made under low plasma fibrinogen levels may be feasible and easily lyzed by fibrinolytic system, which frequently activated by $\mathrm{CPB}$ [21]. Thus, severe hypofibrinogenemia at the removal from CPB leads to uncontrollable microvascular bleeding, e.g., oozing at multiple sites in the surgical field, after completion of surgical hemostasis, resulting in massive hemorrhage.

Accumulating new data including this study suggest that fibrinogen plays a critical role in achieving and maintaining hemostasis, particularly in patients suffering from severe hypofibrinogenaemia during massive bleeding [22]. Because fibrinogen seems to be the coagulation factor first reaching a critically low level $(100 \mathrm{mg} / \mathrm{dL})$ even before thrombocytopenia develops during massive hemorrhage, the hemostatic therapy in this setting should be focused upon quick and enough supplementation of fibrinogen. Although, the target plasma concentration for fibrinogen replacement was predicted by in vitro study to be higher than $200 \mathrm{mg} / \mathrm{dL}$ as only these concentrations optimized the rate of clot formation [23], high plasma fibrinogen levels over $300 \mathrm{mg} / \mathrm{dL}$ may even compensate for low platelet counts [24]. We have conventionally used FFP for the purpose of fibrinogen replacement in intraoperative massive hemorrhage because neither cryoprecipitate nor fibrinogen concentrate has been available for decades in Japan. However, FFP has a low and variable concentration of fibrinogen and cannot be used when targeting a high plasma fibrinogen level. Furthermore, the hemostatic efficacy of FFP has been questioned [8,25]. In fact, the fibrinogen concentration was elevated by only less than $50 \mathrm{mg} / \mathrm{dL}$ after 15 units (i.e., $25 \mathrm{ml} / \mathrm{kg}$ ) of FFP transfusion in TAA surgery (Figure 1), suggesting that it is difficult to reach the fibrinogen concentration over $200 \mathrm{mg} / \mathrm{dL}$ by FFP without volume overload.

Several studies and systematic reviews have suggested that fibrinogen concentrate therapy may be effective in controlling perioperative bleeding and in reducing transfusion requirements as well as blood loss in cardiovascular surgery [25-27]. The remarkable observation in our retrospective study is that administration of fibrinogen concentrate after the $\mathrm{CPB}$ termination sufficiently elevated the plasma fibrinogen concentration for hemostasis in TAA surgery, while only FFP transfusion did not (Figures 1, 2, 3 and 4). The plasma fibrinogen concentration reached 200 to $250 \mathrm{mg} / \mathrm{dL}$ at the end of TAA surgery in patients who received fibrinogen concentrate (Table 1). Also, it appears that enough and repeated supplementation with fibrinogen concentrate in addition to conventional transfusion therapy was strongly associated with decreased blood loss and reduced requirements of RBC, FFP, and PC (Figure 5). The difference in the volume of total blood loss between two groups may be largely attributed to the blood loss 
after CPB because most of blood leaking to surgical field is sucked and re-circulated during CPB. Although four products of fibrinogen concentrate, i.e., Haemocomplettan (CSL Behring, Marburg, Germany), Fibrinogene T1 and Clottagen (LFB, Les Ulis, France), Fibrinogen HT, and FibroRaas (Shangai RAAS, Shangai, China), are currently available in the world, the most widely used agent is Haemocomplettan P, commercialized as Ria-STAP in the U.S.A.. A randomized, placebo-controlled trial to investigate the efficacy and safety of Haemocomplettan P in managing severe perioperative bleeding in aortic repair surgery reported that the transfusion of allogenic blood products was significantly reduced in the fibrinogen concentrate group $[28,29]$. The use of Fibrinogen HT, available in Japan, in the clinical study may limit the possibility of comparison with similar trials. In any case, timely administration of fibrinogen concentrate at the fibrinogen level below $150 \mathrm{mg} / \mathrm{dL}$ after CPB termination may be the indispensable hemostatic therapy in aortic repair surgery, even if fibrinogen concentrate is not yet a standard component of many transfusion protocols. If confirmed in larger prospective randomized studies, fibrinogen concentrate would provide a concrete means of reducing transfusions and contribute to better prognosis of patients receiving thoracic aortic repair.

\section{Conclusions}

The results of this retrospective analysis strongly support that timely administration of fibrinogen concentrate at the fibrinogen level below $150 \mathrm{mg} / \mathrm{dL}$ after CPB termination is effective for hemostasis, and therefore contributes to reduction of blood loss and transfused volumes in patients with TAA surgery.

\section{Abbreviations}

TAA: Thoracic aortic aneurysm; CPB: Cardiopulmonary bypass; FFP: Fresh frozen plasma; RBC: Red blood cell; PC: Platelet concentrate; PT: Prothrombin time; APTT: Activated partial thromboplastin time.

\section{Competing interests}

The authors declare that they have no competing interests.

\section{Authors' contributions}

KY substantially contributed to research design, analyzed data, and drafted the manuscript. AU conceived of studies and shared the overall responsibility with KY. JT revised the manuscript critically. All authors approved the submitted and final version of the manuscript.

\section{Acknowledgements}

The authors thank C. Kato for management of clinical data on transfusion to the patients.

\section{Author details}

'Department of Transfusion Medicine, Nagoya University Hospital, 65 Tsurumai, Showa, Nagoya 466-8560, Japan. ${ }^{2}$ Department of Thoracic Surgery, Nagoya University Hospital, Nagoya, Japan. ${ }^{3}$ Aichi Red Cross Blood Center, Seto, Aichi, Japan.

Received: 30 December 2013 Accepted: 12 May 2014

Published: 19 May 2014

\section{References}

1. Aboulafia DM, Aboulafia ED: Aortic aneurysm-induced disseminated intravascular coagulation. Ann Vasc Surg 1996, 10:396-405.

2. Paparella D, Rotunno C, Guida P, Malvindi PG, Scrascia G, de Palo M, de Cillis E, Bortone AS, de Luca Tupputi Schinosa L: Hemostasis alterations in patients with acute aortic dissection. Ann Thorac Surg 2011, 91:1364-1369.

3. Chandler WL: Effects of hemodilution, blood loss, and consumption on hemostatic factor levels during cardiopulmonary bypass. J Cardiothorac Vasc Anesth 2005, 19:459-467.

4. Rahe-Meyer N, PichImaier M, Haverich A, Solomon C, Winterhalter M, Piepenbrock S, Tanaka KA: Bleeding management with fibrinogen concentrate targeting a high-normal plasma fibrinogen level: a pilot study. Br J Anaesth 2009, 102:785-792.

5. Levi M, Cromheecke ME, de Jonge E, Prins MH, de Mol BJ, Briët E, Büller HR: Pharmacological strategies to decrease excessive blood loss in cardiac surgery: a meta-analysis of clinically relevant endpoints. Lancet 1999, 354:1940-1947.

6. Hiippala ST, Myllyla GJ, Vahtera EM: Hemostatic factors and replacement of major blood loss with plasma-poor red cell concentrates. Anesth Analg 1995, 81:360-365.

7. Levi M, Fries D, Gombotz H, van der Linden P, Nascimento D, Callum JL, Belisle S, Rizoli S, Hardy J-F, Johansson PI, Samama CM, Grottke O, Rossaint R, Henny CP, Goslings JC, Theusinger OM, Spahn DR, Ganter MT, Hess JR, Dutton RP, Scalea TM, Levy JH, Spinella PC, Panzer S, Reesink HW: Prevention and treatment of coagulopathy in patients receiving massive transfusions. Vox Sang 2011, 101:154-174.

8. Yang L, Stanworth S, Hopewell S, Doree C, Murphy M: Is fresh-frozen plasma clinically effective? An update of a systematic review of randomized controlled trials. Transfusion 2012, 52:1673-1686.

9. Bornikova L, Peyvand F, Allen G, Bernstein J, Manco-Johnson MJ: Fibrinogen replacement therapy for congenital fibrinogen deficiency. J Thromb Haemost 2011, 9:1687-1704.

10. Fenger-Eriksen C, Lindberg-Larsen M, Christensen A, Ingerslev J, Sørensen B: Fibrinogen concentrate substitution therapy in patients with massive haemorrhage and low plasma fibrinogen concentrations. $\mathrm{Br} J$ Anaesth 2008, 101:769-773

11. Weinkove R, Rangarajan S: Fibrinogen concentrate for acquired hypofibirinogenaemic states. Transfus Med Rev 2008, 18:151-157.

12. Bell SF, Rayment R, Collins PW, Collis RE: The use of fibrinogen concentrate to correct hypofibrinogenaemia rapidly during obstetric haemorrhage. Int J Obstet Anesth 2010, 19:218-234.

13. Ahmed S, Harrity C, Johnson S, Varadkar S, McMorrow S, Fanning R, Flynn CM, O'Riordan JM, Byrne BM: The efficacy of fibrinogen concentrate compared with cryoprecipitate in major obstetric haemorrhage - an observational study. Transfus Med 2012, 22:344-349.

14. Fries $D$, Mortini W: Role of fibrinogen in trauma-induced coagulopathy. Br J Anaesth 2010, 105:116-121.

15. Rourke C, Curry N, Khan S, Taylor R, Raza I, Davenport R, Stanworth S, Brohi K: Fibrinogen levels during trauma hemorrhage, response to replacement therapy, and association with patient outcomes. J Thromb Haemost 2012, 10:1342-1351.

16. Rahe-Meyer N, Solomon C, Winterhalter M, Piepenbrock S, Tanaka K, Haverich A, Pichlmaier M: Thromboelastmetry-guided administration of fibrinogen concentrate for the treatment of excessive intraoperative bleeding in thoracoabdominal aortic aneurysm surgery. J Thorac Cardiovas Surg 2009, 138:694-702.

17. Solomon C, Picklmaier U, Schoechl H, Hagl C, Raymondos K, Scheinichen D, Koppert W, Rahe-Meyer N: Recovery of fibrinogen after administration of fibrinogen concentrate to patients with severe bleeding after cardiopulmonary bypass surgery. Br J Anaesth 2010, 104:555-562.

18. Bolliger D, Görlinger K, Tanaka KA: Pathophysiology and treatment of coagulopathy in massive hemorrhage and hemodilution. Anesthesiology 2010, 113:1205-1219.

19. Chung JH, Gikakis N, Rao AK, Drake TA, Colman RW, Edmunds LH Jr: Pericardial blood activates the extrinsic coagulation pathway during clinical cardiopulmonary bypass. Circulation 1996, 93:2014-2018.

20. Weerwind PW, Lindhout T, Caberg NEH, de Jong DS: Thrombin generation during cardiopulmonary bypass: the possible role of retransfusion of blood aspirated from the surgical field. Thromb / 2003, 1:1-9. 
21. Ide M, Bolliger D, Taketomi T, Tanaka KA: Lessons from the aprotinin saga: current perspective on antifibrinolytic therapy in cardiac surgery. $J$ Anesth 2010, 24:96-106

22. Levy JH, Szlam F, Tanaka KA, Sniecienski RM: Fibrinogen and hemostasis: a primary hemostatic target for the management of acquired bleeding. Anesth Analg 2012, 114:261-274.

23. Bolliger D, Szlam F, Molinaro RJ, Rahe-Meyer N, Levy JH, Tanaka KA: Finding the optimal concentration range for fibrinogen replacement after severe haemodilution: an in vitro model. Br J Anaesth 2009, 102:793-799.

24. Lang T, Johanning K, Metzler H, Piepenbrock S, Solomon C, Rahe-Meyer N, Tanaka KA: The effects of fibrinogen levels on thromboelastometric variables in the presence of thrombocytopenia. Anesth Analg 2009, 108:751-758.

25. Kozek-Langenecker S, Sørensen B, Hess JR, Spahn DR: Clinical effectiveness of fresh frozen plasma compared with fibrinogen concentrate: a systematic review. Crit Care 2011, 15:R239.

26. Danes AF, Cuenca LG, Bueno SR, Barrenechea LM, Ronsano JBM: Efficacy and tolerability of human fibrinogen concentrate administration to patients with acquired fibrinogen deficiency and active or in high-risk severe bleeding. Vox Sang 2008, 94:221-226.

27. Warmuth M, Mad P, Wild C: Systematic review of the efficacy and safety of fibrinogen concentrate substitution in adults. Acta Anaesthesiol Scand 2012, 56:539-548.

28. Rahe-Meyer N, Solomon C, Hanke A, Schmidt DS, Knoerzer D, Hochleitner G, Sørensen B, Hagl C, Pichlmaier M: Effects of fibrinogen concentrate as first-line therapy during major aortic replacement surgery: a randomized, placebo-controlled trial. Anesthesiology 2013, 118:40-50.

29. Rahe-Meyer N, Hanke A, Schmidt DS, Hagl C, Pichlmaier M: Fibrinogen concentrate reduces intraoperative bleeding when used as first-line hemostatic therapy during major aortic replacement surgery: results from a randomized, placebo-controlled trial. $J$ Thorac Cardiovasc Surg 2013, 145:S178-S185.

doi:10.1186/1749-8090-9-90

Cite this article as: Yamamoto et al:: Fibrinogen concentrate administration attributes to significant reductions of blood loss and transfusion requirements in thoracic aortic repair. Journal of Cardiothoracic Surgery 2014 9:90

\section{Submit your next manuscript to BioMed Central and take full advantage of:}

- Convenient online submission

- Thorough peer review

- No space constraints or color figure charges

- Immediate publication on acceptance

- Inclusion in PubMed, CAS, Scopus and Google Scholar

- Research which is freely available for redistribution 